\title{
CINEMA DOCUMENTAL E REALIDADE SOCIAL ${ }^{1}$
}

Luiz Eduardo Jorge $\mathbf{~}^{2}$

\section{Introdução}

O Cinema nasceu documental, social e silencioso.

Do Fuzil Fotográfico de Etienne- Jules Marey, criado em1882, ao Cinetoscópio de Thomas Alva Edison em 1894, e seu aperfeiçoamento físico, químico e óptico no Cinematógrafo Lumière, no ano de 1985, o Cinema, do latim Kinéma, ato, movimento, materializa na película o olhar imagético sobre o mundo, numa abordagem documental.

O cinema se consolidou na estética da observação da representação da vida social.

Dos planos fixos de Edison, sobre as danças Sioux no Black Maria, primeiro estúdio de cinema construído a West Orange na periferia de Nova Iorque, às imagens em movimento da "Saída dos Operários da Fábrica", "O Almoço do Bebê" e a “Chegada do Trem na Estação", filmados pelos irmãos Lumière, no final do século XIX, o cinema atesta e reflete sua rubrica documental, originando-se de uma realidade social.

Logo depois, na aurora do século XX, com a magia de Georges Meliès, o enquadramento fixo da imagem por meio da nova tecnologia cinematográfica cedeu lugar ao ilusionismo dos efeitos especiais da sobreposição de imagens em planos fixos, como forma de encantar a realidade social, hipnotizando o espectador para diverti-lo e entretê-lo por meio da projeção na tela branca do cinema.

Sur le plan de l'art, Méliès, nous le verrons, fut le premier à introduire la notion de mise en scène au cinema. Mais sur lê plan qui nous retinet ici, on peut dire qu'il fut le premier - et le seul en 1897 - à fonder une industrie sur la production et la vente des films quand les autresn'en faisainet que pour assurer le placement et la bonne marche d'un appareil. Les uns sont des inventeurs qui cherchent à créer une industrie ayant pour objet la construciton et la vente d'une caméra, l'autre est un homme de théâtre qui cheche à tier parti du spectacle obtenu au moyen de cette caméra. (Mitry, 1967: 94).

\footnotetext{
${ }^{1}$ Artigo apresentado no $34^{\circ}$ Encontro Anual da ANPOCS, Mesa Redonda: Imagens e interpretações: a pesquisa social em áreas e situações de conflito e tragédia, em outubro de 2010.

${ }^{2}$ Cineasta; Professor titular do Programa de Pós-Graduação em História e pesquisador do Instituto Goiano de Pré-História e Antropologia da Pontifícia Universidade Católica de Goiás - PUC Goiás.
} 
Da novidade do cinema de produzir, fazer surgir e desaparecer na tela imagens em movimento, para dar vida ao mundo real e à fantasia, através de um novo aparelho técnico de projeção, estava concebida e inaugurada uma ferramenta complexa, nos tempos da Revolução Industrial: a máquina de fabricar e projetar imagens na escuridão da sala de cinema. O sonho remoto do homem, ao retratar o mundo real na plasticidade da imagem pela percepção artística, estava realizado.

Desde o dia 28 de dezembro de 1895, quando se realizou a primeira projeção de documentários no Grand Café de Paris ${ }^{3}$, até nossos dias, as imagens em movimento, a televisão e ultimamente as novas tecnologias imagéticas, vão gerando uma complexa realidade virtualmente constituída.

O espetáculo cinematográfico, televisivo e as novas tecnologias digitais invadiram todo o espaço social, reduzindo o espectador à impotência, à passividade de vítima. Alguns estudiosos da comunicação social usam a expressão colonização eletrônica para explicar os efeitos sociológicos dessa invasão cultural.

\begin{abstract}
A tela da tevê continua sendo uma superfície limitada, mas a escuridão não mais impera: visíveis à nossa volta estão os objetos do cotidiano - livros, cadeiras; o telefone toca; nós nos levantamos para beber alguma coisa, conversamos. Nessa zona menos escura, onde podemos até deixar as luzes acesas, outras imagens e outros sons competem discretamente com a televisão. Adeus à reclusão monástica da sala de cinema. Instale-se a realidade, com suas sutilezas e tentações. Estamos em casa. (Carrière, 1995:66).
\end{abstract}

O aprimoramento vertiginoso da tecnologia audiovisual e das comunicações está gerando, muito rapidamente, meios sofisticados para a síntese de imagens que, pelo volume subseqüente dos quadros imagéticos apresentados, não permite ao espectador o discernimento da fronteira ente realidade e ficção. Nesta situação, o espectador aceita passivamente e crê em tudo que a TV apresenta, não possibilitando a reflexão e a análise do conteúdo do que está sendo veiculado. O tomismo é, neste momento, discutível. A fé se sobrepõe à razão, a crença no que está sendo visto é imediata.

\footnotetext{
3 "No dia 22 de março de 1895, os Luimière fazem uma primeira demonstração de seu equipamento perante um amplo público. Trata-se da Société d'Encouragement pur l'Industrie Nationale. O filme exibido foi La Sortie des Usines. Várias outras sessões demonstrativa foram até que, em 28 de dezembro de 1895, num modeste oprão do Grand Café, ponposamente chamado, por sua extravagante decoração, de Salon Indien, 35 espectadores pagaram 1 franco para asistirem a uma série de curtas projeções cinematográficas: A saída dos operários das usinas Lumière, A chegada do trem na estação, $\mathrm{O}$ almoço do bebê e O mar são alguns dos filmes apresentados. Não nascia o cinema. Apenas se prostituía. E barato" (GUIDI, 1991: 162).
} 
Há uma lógica da imagética televisiva que nos anula do mundo social, do mundo em que somos atores sociais. Faz-nos perder a condição de críticos, transformando-nos em meros espectadores. Aceitamos deliberadamente tudo que a TV nos transmite. Esquecemo-nos de nós mesmos e passamos a viver em um mundo irreal, de dezenas, de centenas de imagens por minuto, alienados da realidade oculta do ambiente metropolitano que habitamos. Como enfatiza Carrière: "essas imagens (deveríamos achar um nome para elas) cumprem a mesma função que muzak. Elas criam um véu entre nós e a realidade; escondem-nos o mundo" (Carrière, 1995:69).

Entretanto, é preciso analisar a produção cinematográfica para além de seu veículo divulgador, ou seja, considerá-la a partir da especificidade de sua composição imagética. Seja o cinema ficcional, seja o cinema documental, o que distingue a obra é a intencionalidade de quem a produziu, intencionalidade que se desgarra do autor para impregnar a obra concluída, dando-lhe autonomia. Neste sentido, o cinema é representação da realidade, é recorte intencional da realidade representada por meio da imagem, constituindo-se como uma forma de comunicação que revela uma determinada compreensão do contexto sócio-histórico em que vivemos ${ }^{4}$. Mesmo sendo representação da realidade, o cinema é documental porque registra por meio da imagem o pensamento e as idéias que gestam embates e conflitos, convergências e divergências dos sujeitos que cotidianamente protagonizam o movimento da história. Assim, é no interior da contradição forma/conteúdo, ficção/realidade que o cinema se faz como registro imagético da história, tornando o acúmulo da produção cinematográfica registro histórico da vida social.

Contudo, o cinema documental é também um gênero cinematográfico que por definição se origina de uma realidade, que se amplia na dialética sujeito-objeto e se dinamiza na complexidade da realidade cotidiana.

Sabe-se que toda obra audiovisual de caráter documental contém, desde o seu enunciado, a intenção de mostrar alguma realidade e que, obviamente, conjuga a ideologia do autor e alguma proposta formal para representar essa realidade. Objetividade e subjetividade são valores que se confundem imperceptivelmente na

\footnotetext{
${ }^{4} \mathrm{O}$ termo representação está sendo aqui empregado para designar “ as formas de conhecimento que se manifestam como elementos cognitivos (imagens, conceitos, categorias, teorias), mas que não se reduzem apenas aos conhecimentos cognitivos. Sendo socialmente elaboradas e compartilhadas, contribuem para a construção de uma realidade comum, possibilitando a comunicação entre os indivíduos. Dessa maneira, as representações são fenômenos sociais que têm de ser entendidos a partir do seu contexto de produção, isto é, a partir das funções simbólicas e ideológicas a que servem e das formas de comunicação onde circulam”. (Alexandre, 2004 ,p. 131).
} 
leitura de uma obra audiovisual. É imprescindível, então, que o autor busque um equilíbrio de valores proporcionais à complexidade do tema, o que nem sempre é fácil em função de suas preferências estéticas, dos critérios éticos e dos interesses em jogo.

O que está em questão é o encontro da subjetividade do cineasta com a objetividade provocada pela sua interação com os sujeitos da cultura. Desta perspectiva, o respeito e a natureza do processo interativo que se pretende alcançar pela pesquisa social que antecede a realização propriamente dita do cinema documental, decorrem da atitude do cineasta, mas estão, ao mesmo tempo, para além dele, em função das questões que aborda e que não se limitam tão-somente à exterioridade do trabalho de observação da vida humana e da sua descrição sistemática por meio de registros imagéticos.

Conduzido pela consciência da função social e política que representa a produção documental, o cineasta deverá orientar-se por uma postura ética que aponta para a responsabilidade com o rigor, com a fidelidade e a veracidade do conteúdo da obra cinematográfica realizada.

John Grierson, principal impulsor do movimento da escola documental inglesa entre 1929 e 1946, foi o sociólogo-cineasta que teorizou e utilizou pela primeira vez o termo documental para conceituar as obras cinematográficas que se propõem apreender temas da realidade, evitando o cinema espetacular. Foi Grierson quem definiu a obra documental como "elaboração criativa da realidade", chamando a atenção para o compromisso ético que deve assumir o cinema documental, evitando recorrer a enganos artificiosos para encantar facilmente o espectador. Tomando de empréstimo a expressão documental utilizada pelos viajantes franceses para se referirem ao cinema de viagens ou exótico afirmou:

Mi argumentación separada para el documental es simplemente que en su uso del artículo vivo existe asimismo una oportunidad de realizar un trabajo creativo. Quiero singnificar, también, que la elección del medio expresivo que es el documental, es una elección tan gravemente distinta como puede serlo el elegir de la ficción. Ocuparse de un material diferente es, o debe ser, ocuparse de temas estéticos distintos a los del estúdio. Formulo esta distinción para afirmar que el joven director no puede, naturalmente, acceder al documental y al estilo del estúdio a la vez (Grierson ,1985: 146).

Este autor postulava que na especificidade do cinema documental de mover-se, observar e selecionar a realidade para apanhá-la em seu ritmo original, encontram-se os princípios que se traduzem como guia para a interpretação cinematográfica do mundo 
contemporâneo. Entretanto, realidade e criatividade não são valores opostos para Grierson, a criatividade é um dos traços relevantes para a expressão imagética da realidade. Por definição, uma obra documental deve apreender o especifico e expressálo de uma maneira original, compreendendo que, nessa expressão original, a morfologia referente a essa realidade é um dos vetores essenciais da especificidade.

Assim, como um realizador pode inserir-se em um grupo social tomado com tema e objeto da pesquisa para a produção audiovisual do gênero documental, sem considerar, ao mesmo tempo, a necessária criatividade e o rigor da veracidade? Que objetividade pode assumir o pesquisador-cineasta diante da realidade observada?

O movimento do cinema de autor, desencadeado pelo Cahiers du Cinema, no início da década de 1950, defendia a sua especificidade de sempre estar interessado em abordar o diferente para expressá-lo a partir de sua própria visão de mundo.

Aqui, Autor é o diretor cinematográfico, um conceito iluminado pelo cineasta francês Jean Renoir nos anos 1930. Este conceito foi apropriado por Glauber Rocha, autor do clássico Deus e o Diabo na Terra do Sol, que postulava o cinema político, social e cultural alternativo, como forma de abordar a realidade social brasileira a partir de temas contemporâneos. Cinema que faria o contra-campo do "star sistem", não comercial, para falar da pobreza, da fome, do campo, da exclusão social e das contradições do modelo econômico vigente. Em "A revolução do cinema novo", Glauber apresentou sua abordagem revolucionária do cinema militante comprometido com a crítica social e histórica brasileira. Embora seja cinema ficcional, a obra de Glauber trata de temas da especificidade social e cultural brasileira.

Tendo como referência as matrizes conceituais que deram origem ao cinema documental, apresentamos a seguir o argumento que orientou a realização do curta metragem que aborda o acidente radioativo ocorrido na cidade de Goiânia, no ano de 1987.

\section{“Césio 137, o brilho da morte" - acidente radiológico de Goiânia}

O título do filme foi extraído do enunciado de uma das vítimas do acidente: "eu me apaixonei pelo brilho da morte".

O filme parte da discussão das conseqüências de um acidente radiológico provocado pelo contato de grupo de pessoas com Césio-137. Metal pesado, não emana vapores nem gases, o seu núcleo é constituído por 55 prótons e 82 nêutrons, por isso a soma de massa atômica 137, libera radioatividade (raios gama), invisível, azul quando 
as suas partículas são expostas em ambientes escuros, penetra silenciosamente no corpo humano através dos poros e contamina o meio ambiente colocando em perigo a vida na terra.

O filme "Césio 137- O Brilho da Morte", aborda o resgate da trajetória histórica do maior acidente radiológico do mundo, sobretudo pela incursão na paisagem interior das vítimas que tiveram contato direto e indireto com partículas da cápsula de Césio137, violada de um aparelho de radioterapia abandonado nos escombros do extinto Instituto Goiano de Radioterapia, em Goiânia, no dia 13 de setembro de 1987.

O documentário trata do universo psicológico projetado nos fenômenos de pânico, dor, medo, dúvida, isolamento e discriminação por que passaram e passam ainda as vítimas que não tinham conhecimento do perigo que representava o "brilho da morte" nos $19 \mathrm{~g}$ de partículas radioativas que manipularam. Por outro lado, aprofunda as contradições da política nuclear e a negligência na fiscalização dos órgãos oficiais no controle e manutenção das máquinas de radioterapia, como a que causou a referida tragédia, afetando a integridade física, desconstituindo a subjetividade e a identidade de centenas de pessoas, provocando mortes, atingindo uma área de $2000 \mathrm{~m} 2$, acumulando 13.500 toneladas de lixo radioativo que foram transferidos para um depósito, construído a céu aberto na cidade de Abadia de Goiânia.

"O Brilho da Morte", estrutura-se com base nas crônicas das vítimas sobreviventes do acidente com o Césio 137 e o pronunciamento da Promotoria Pública, tendo como peça principal o Processo Criminal e o material documental de imagem em movimento e de arquivo fotográfico público e privado.

Para dar a dimensão histórica e sociológica do acidente, o filme contextualiza a tragédia com o Césio 137 no âmbito da política da Energia Nuclear, verificando os principais acidentes nucleares que aconteceram em diversos continentes a partir de 1957, sendo o primeiro deles, o acidente atômico registrado na Usina de Liverpool, na Inglaterra, passando pela Segunda Guerra Mundial com a bomba atômica de Hirochima e Nagazake, o acidente russo de Tchernobil, chegando aos dias atuais com o exemplo do vazamento de Angra dos Reis. Ao registrar esses acidentes o filme alerta para o constante perigo do uso da energia nuclear para à vida neste planeta.

O filme foi produzido e realizado entre 2003 e 2004, ano de latência da Bomba de Césio 137, extraída de um aparelho de radioterapia abandonado, que continha esse elemento radioativo e que foi o responsável pela contaminação de dezenas de pessoas. 
O referido aparelho não foi removido dos escombros do prédio onde funcionava o Instituto Goiano de Radioterapia em função de um litígio judicial.

Os catadores de papel Wagner Mota Pereira e Roberto Santos Alves apanharam o cilindro com a cápsula de Césio 137 na casamata da sala de radioterapia do referido instituto, na Avenida Paranaíba com a Tocantins, no dia 13 de setembro de 1987. O arrombamento da capa protetora ocorreu no dia seguinte na residência de Wagner Mota na Rua 57, Centro. Os efeitos da radiação foram identificados por um farmacêutico dois dias depois, através de queimaduras nas costas da mulher de Wagner.

A polícia Federal pôde reconstituir parcialmente o percurso das partes do aparelho de radioterapia com dados fornecidos por Wagner, Roberto, Devair Alves e Kardec Sabastião Rodrigues e pelos médicos Carlos Bezerril, Orlando Teixeira e Criseide Dourado. O Superintendente da Polícia Federal, Francisco de Barros Lima, afirmou que todas as fases do acidente ocorreram no mês de setembro daquele ano.

No dia 19 de setembro, Devair Alves e Kardec Sebastião apanharam na casamata do Instituto de Radioterapia a carcaça de chumbo, pesando 303 quilos, que abrigava o cilindro levado por Roberto e Wagner. Neste período, todas as pessoas envolvidas com as peças já sabiam dos problemas físicos e orgânicos provocados pela radiação identificada pelo farmacêutico, de nome não citado pela polícia.

Com graves queimaduras, Wagner Mota procurou a Clínica Santa Catarina para uma consulta. O médico Carlos Evangelista da Rocha o atendeu e diagnosticou uma dermatitie actinica, típica nos casos de excesso de radiação. Esta informação foi fornecida pelo advogado Wanderley de Medeiros depois de confirmar os fatos com os médicos acusados no acidente. O médico Carlos Evangelista não foi localizado em sua residência.

No dia 29 de setembro, a Vigilância Sanitária da Osego telefonou ao Corpo de Bombeiros solicitando a retirada de uma peça que emanava um gás venenoso. Os quatro militares que foram ao local, na Rua 16-A, Setor Aeroporto, sofreram a contaminação por radiação sem saberem do que se tratava. Neste mesmo dia, o caso tornou-se público e a Vigilância Sanitária informou que na mesma data teria recebido a peça com o Césio 137, entregue pelos catadores de papel.

Passados 15 anos do acidente radiológico, a imagem da tragédia permanecia no corpo e na memória das vítimas oficialmente reconhecidas e, a cada dia que passa, para além dos casos de crianças que nascem com malformação congênitas - hidrocefalia, coluna exposta, atraso no crescimento -, surgem novas vítimas anônimas com 
manifestações de doenças e sintomas físicos em conseqüência dos efeitos da radiação através do Césio-137.

Com base num balanço histórico, o documentário procurou identificar uma diversidade de narrativas sociais advindas do cotidiano da população atingida direta e indiretamente pela radiação para compô-las e, também, para contrapô-las às crônicas do poder político local e nacional. A elaboração do roteiro do filme teve como principal objetivo descortinar os mistérios, as ações e omissões dos representantes dos órgãos oficiais responsáveis pela política administrativa e nuclear brasileira.

Teve, ainda, como propósito abordar no tempo e no espaço a verdadeira história do acidente radiológico com o Césio 137 a fim de revelar os protagonistas, seus ambientes, seus sonhos e suas desilusões como peça documental que pudesse cumprir o objetivo social de confrontar as vítimas reconhecidas e as vítimas anônimas com o poder público.

Finalmente, o filme buscou refletir sobre a Política Nuclear Brasileira com a finalidade de despertar a consciência e o respeito à vida humana e ambiental.

A pesquisa e o argumento do filme foram elaborados a partir de relatos da história oral, gravados em suporte vídeo digital com grande parte das vítimas do acidente, bem como, com as informações extraídas da imprensa escrita e televisiva, associadas às pesquisas cientificas realizadas por pesquisadores do campo da Geografia, Serviço Social, Química, Biologia, Física, Antropologia, Sociologia, Direito e Psicologia.

Desta forma, a abordagem do argumento que se segue, tece um universo complexo de dados aqui descritos como forma de elucidar a fidelidade e originalidade documental destas pesquisas, com a intenção de aprofundar e ampliar o máximo possível a dimensão da construção do roteiro, peça e guia fundamental na realização do filme. Neste sentido, proponho a seguir uma descrição mais detalhada do cenário urbano, humano e ambiental do contexto etnográfico do acidente com o Césio 137.

Tarde de Domingo, 13 de setembro de 1987. Dois sucateiros/catadores de papel, Roberto Alves e Wagner Mota Pereira, dirigiram-se para as ruínas de um prédio onde antes funcionava o Instituto Goiano de Radioterapia, no local denominado "buraco da Santa Casa", no centro de Goiânia, capital do Estado de Goiás. O endereço exato é na Avenida Paranaíba, $\mathrm{n}^{\circ} 1587$, de onde os dois removeram um velho equipamento de radioterapia na intenção de extraírem o chumbo que recobria o mesmo, já que o aparelho estava ali abandonado como sucata. 
Assim, pensaram em fazer algum dinheiro vendendo a sucata de chumbo a um dos ferros-velhos da cidade e ali mesmo, nos escombros do prédio demolido alguns anos antes, Roberto e Wagner conseguiram dividir a peça em duas partes. Recolheram uma delas e, com a utilização de um carrinho de mão, a transferiram para a casa de Roberto - situada no no 68 da Rua 57, do Setor Central - onde tentaram separar a parte de chumbo do restante do equipamento, utilizando ferramentas comuns.

Com essa atividade, ignorando completamente o perigo que corriam, romperam o lacre de proteção de uma cápsula de Césio 137, localizada no interior do aparelho, liberando alta radioatividade. Assim, deram início ao episódio que foi qualificado por autoridades da área nuclear, como o maior acidente radiológico do mundo ou como o maior acidente radioativo do Ocidente.

Abria-se uma Caixa de Pandora, cujo conteúdo era inteiramente desconhecido da grande maioria da população - inclusive de técnicos, que só o conheciam por meio de literatura científica especializada ou por manipulação em estudos de laboratórios - e daqueles que, involuntariamente, causaram sua liberação.

A partir do momento em que o lacre do equipamento foi violado, a radiação foi sendo liberada, atingindo as pessoas que manipularam partículas de Césio 137 como uma sucata qualquer. Com o passar das horas e dias o fato foi se agravando, com a contaminação cada vez maior de pessoas que se relacionavam pessoalmente ou profissionalmente com estas duas primeiras vítimas. Os dois sucateiros conseguiram passar a peça adiante para os donos de um ferro velho, os irmãos Devair e Ivo Alves Ferrreira. A partir deles mais pessoas viriam a ser contaminadas pois, ignorando completamente a periculosidade do conteúdo da peça, foram se envolvendo numa trama cujo ponto central era a atração exercida por uma luz emitida do interior da peça, um brilho azul que descreveram como sendo de grande beleza. O inocente pó que saia do interior da peça era passado de mão em mão, transferido para os corpos de outras pessoas como se fosse purpurina em meio a uma festa. Os parentes mais próximos de Devair, os vizinhos, clientes a procura de outras peças, movidos pela curiosidade e pela cobiça, querendo saber do que se tratava e se tinha valor, foram espalhando o pó pelo bairro e pela cidade.

O desconhecido pó atraiu pessoas. De tão lindo foi passado pelo corpo de uma mulher (Luiza Odete), por seu marido (Kardec). Foi ingerido por uma criança (Leide das Neves). Foi posto no bolso da calça de um e da camisa de outro. Porém horas depois as pessoas começavam a sentir seus efeitos e, aos poucos vários contaminados 
foram dando conta de que o que havia em comum entre eles era o pó. Sem melhoras, foram procurando ajuda em farmácias, hospitais, postos de saúde, e até foram tratados como portadores de alguma doença infecto-contagiosa. Por fim, Maria Gabriela, esposa de Devair, desconfiada da peça, levou os restos da mesma à Vigilância Sanitária para ser examinada. Desta forma um médico suspeitou de contaminação radioativa, consultou um físico da cidade que confirmou o fato e o alarme foi dado. $\mathrm{O}$ objeto coberto de chumbo era uma Bomba de Césio 137.

Enquanto tudo isso acontecia, lentamente as partículas de Césio atingiam a cidade através de pessoas, da rede de esgoto diretamente para os córregos, pela água da chuva que corria nas ruas atingiu linhas do transporte coletivo através de outro envolvido, o Sr. Odesson, irmão de Devair. Ele colocou uma pequena porção do pó na palma da mão e esfregou com o dedo indicador da outra mão, não dando maior importância ao fato, lavou a mão e foi trabalhar. Com certeza enviou para o esgoto uma porção, deixando outra no volante e painel do ônibus no qual trabalhava.

Como conseqüência, os efeitos do acidente foram atingindo homens, mulheres, crianças, animais domésticos, casas, ruas, chegando até a atmosfera, colocando em risco toda uma cidade e o meio ambiente local. A radiação, oficialmente, atingiu uma área de $2.000 \mathrm{~m} 2$ - não contínuos - infiltrando-se no solo, em alguns pontos, em até $50 \mathrm{~cm}$ de profundidade, provocando a necessidade de derrubada de árvores e plantas que sofreram contaminação, num raio de $100 \mathrm{~m}$ das zonas afetadas.

A partir da confirmação da contaminação por Césio 137 a Comissão Nacional de Energia Nuclear foi contactada e enviou seus técnicos para Goiânia. Começaria a descontaminação das áreas afetadas e das pessoas diretamente contaminadas, assim como a triagem do restante da população.

Neste momento, a imprensa local e nacional, começou a divulgar os fatos causando choque nas famílias contaminadas e, em seguida, em toda a sociedade. Em decorrência das peculiaridades do acidente, criou-se a necessidade de fazer circular, entre a população, uma série de informações normalmente restritas ao campo da ciência e da tecnologia. A transmissão rápida dessas informações ocorreu, principalmente, por meio da utilização dos meios de comunicação de massa: imprensa e as redes de rádio e televisão. Tratava-se de informar o significado básico dos elementos que provocaram o acidente e seus efeitos. Quando o acontecimento veio a público, os atingidos pela radioatividade já manifestaram todos os seus sintomas - tais como náuseas, vômitos, diarréias, dores de cabeça, febre, perda de apetite, perda dos pêlos, radiodermites - em 
decorrências de altas doses de radiação a que foram submetidos e do transcurso de um significativo período de tempo entre o momento em que foram atingidos e que o acidente chegou ao conhecimento das autoridades públicas. O brilho e a intensa luz azul emitida pela sucata de chumbo se transformavam em tragédia, trazendo dor, dúvida, medo e incertezas.

A intimidade das famílias foi bruscamente violada. Foram informadas de que suas casas teriam que ser desocupadas e seus pertences estavam contaminados. Seriam transformados em lixo (radioativo). Uma base de descontaminação foi montada no Estádio Olímpico, no Centro de Goiânia. Ali as pessoas entravam para serem monitoras por estranhos aparelhos que mediam o grau de contaminação. Neste processo de identificação das pessoas atingidas muitas foram obrigadas a deixar as roupas, calçados, bolsas, relógios, jóias, dinheiro, tudo. Seguiam nuas para banhos de mangueira, em vinagre e produtos químicos que lhes "retirariam" o Césio de seus corpos. Marly, uma das vítimas, relata a humilhação passada no momento do banho público lembrando as ações dos antigos campos de concentrações do Nazismo.

Os albergues preparados para os contaminados em escolas públicas, igrejas e centros comunitários ficaram lotados. Os contaminados mais graves seguiram para os hospitais. O Hospital Geral abrigou dezenas de radioacidentados por vários meses. $\mathrm{O}$ confinamento prolongado, a solidão forçada e as relações afetivas cortadas, resultaram em um vazio existencial para várias pessoas, gerando depressão e sérios problemas psicológicos. Ao Hospital Naval Marcílio Dias, localizado no Rio de Janeiro, foram encaminhadas as vítimas mais graves: quatro foram a óbito.

Segundo informações de técnicos da CNEN, foram demolidas sete casas. Porém, sabe-se que essas demolições atingiram um número maior de famílias, em decorrência da forma de ocupação do espaço urbano em que aconteceu o acidente. Sendo uma área habitada por pessoas de baixa renda familiar, o lote é utilizado de forma a maximizar sua ocupação. Assim, habitualmente, constrói-se uma residência, de padrão um pouco melhor, na frente do lote, normalmente utilizada por seu proprietário, e uma quantidade de outras residências, de padrão mais modesto, no fundo do lote, que são ou alugadas, como estratégia para aumentar a renda familiar, ou utilizadas para residência de outros membros da família, como os filhos que se casam. Na casa em que morava Roberto Santos Alves, por exemplo, foi registrada a demolição de duas casas. Entretanto, além da ocupação da residência da frente do lote, nos barracões do fundo habitavam três famílias. Portanto, foram demolidas quatro residências. 
Alguns parentes dos primeiros contaminados moravam em áreas distantes da cidade e, até mesmo, em outros municípios, de forma que a contaminação atingiu inúmeras localidades se multiplicando invisível e perigosamente.

Odesson, motorista do transporte coletivo urbano foi altamente contaminado e contaminou sua casa e família. Ele era também proprietário de uma granja de suínos, aves de corte e criador de pássaros silvestres, no município de Aparecida de Goiânia. Seus animais foram identificados como contaminados, sendo sacrificados tornando-se lixo radioativo. Sua cunhada, Carmelita, faleceu alguns meses depois e teria sido a única a ingerir ovos daquela criação. O laudo médico identificou contaminação pelo Césio 137.

A descontaminação da cidade durou vários meses. Gerou $6.500 \mathrm{~m} 3$ de rejeitos radioativos que foram transferidos para um depósito provisório em Abadia de Goiás, em cuja área, posteriormente, foi construído o depósito definitivo. Foram oficialmente consideradas contaminadas ou irradiadas 249 pessoas. Destas, quatro morreram inicialmente, onze posteriormente e as outras ficaram marcadas por seqüelas, ao lado dos efeitos desconhecidos que poderão atingir as gerações futuras.

Assim, ao mesmo tempo em que o acidente era apresentado ao público e se impunha, por força de seu ineditismo, como matéria de todos os meios de comunicação, já se podia observar objetivamente os efeitos da radiação sobre aqueles que haviam sido submetidos à exposição de altas doses. Em razão de a radioatividade ser silenciosa, invisível, inodora e indolor; de seus efeitos, quando o indivíduo é submentido a uma baixa dose, geralmente manifestarem-se a longo prazo; e, ainda mais, da impossibilidade de se estabelecer rapidamente a rota de disseminação da radioatividade pelo espaço e pelos grupos de pessoas atingidas, a população de Goiânia viu-se em um estado emocional de perplexidade, seguido de medo e pânico.

Ao divulgarem o acidente, os meios de comunicação começaram, simultaneamente, acrescentando aos sintomas já citados o comprometimento genético, o câncer e, no limite, a morte. Neste contexto, muitos dos habitantes da cidade foram apossados do medo de estarem contaminados ou irradiados. Diante do sentimento de ameaça de que a população se viu tomada ante as recomendações difundidas pelos técnicos (que os habitantes da cidade evitassem trafegar pelas áreas contaminadas e evitassem contato com as pessoas já identificadas como expostas à radiação - medidas necessárias para conter a expansão do acidente), o público elaborou essas informações e adotou um comportamento de discriminação, inicialmente em relação aos atingidos e, 
posteriormente, em relação a todos os moradores das áreas em que os focos mais graves foram identificados. Em seguida, esse comportamento discriminatório foi estendido para os produtos e serviços comercializados nos bairros identificados como áreas do acidente.

O medo de contato com pessoas e mercadorias irradiadas não se circunscreveu à cidade de Goiânia. Seus moradores, bem como os do Estado de Goiás, tiveram canceladas reservas em hotéis de todas as grandes cidades do país e de casas de veraneios nos principais balneários e, no limite, tiveram carros depredados, pelo simples fato de portarem placas de Goiânia, em cidade como São Paulo e Brasília.

O acidente com o Césio 137 gerou perplexidade, inquietação, medo e pânico que se disseminaram na sociedade goiana, em particular, e na sociedade brasileira, em geral. Pelas suas peculiaridades, o acidente constitui-se em um fenômeno singular que não pode ser restringido às explicações de cunho físico ou biológico. Por exigir outra abordagem, tornou-se relevante utilizar os recursos da pesquisa no campo das ciências humanas e sociais - antropológica, sociológica e psicológica - para avançar no conhecimento do episódio em si, e no conhecimento dos processos societários que ele contribuiu para revelar.

No âmbito do senso comum, elaboraram-se explicações, usualmente aceitas em torno do acidente, de que a perplexidade, o medo e o pânico, sentimentos estes vividos, de maneira diferenciada mas generalizada pela população, decorreram da forma como o acontecimento foi divulgado pela imprensa. Desta forma, pretendemos, neste projeto fílmico, demonstrar que a explicação para esses sentimentos não se restringem à forma de sua divulgação, mas está relacionada também com as representações sociais e psicológicas que a sociedade construiu em torno da questão nuclear. Foram elas que informaram as atitudes dos diferentes segmentos sociais em face do acidente.

Transcorridos quinze anos o número de vítimas aumentou pelos seus efeitos genéticos o que nos conduz abordar as crônicas dos sobreviventes e da diversidade de problemas atuais gerados neles em decorrência da contaminação pelo Césio 137: suicídios, depressão, isolamento, discriminação, abandono, câncer e mutilações.

\section{Representação imagética da realidade social}

A questão do método de pesquisa para apreender o contexto social específico, torna-se complexo na medida em que o pesquisador-cineasta ou o cineasta-autor se propõe representar uma realidade cultural ou social em que ele deverá interpretá-la à 
partir dos códigos do próprio grupo à exemplo de minorias culturais ou grupos sociais discriminados, como é o caso das vítimas do acidente radiológico com o Césio 137, na cidade de Goiânia em setembro de 1987, em que a tragédia em si mesma mudou por completo o comportamento humano e social.

Neste caso especifico do maior acidente radiológico do mundo, o desenvolvimento da pesquisa se deu com base nas narrativas orais e das imagens de arquivo disponíveis sobre o contexto histórico das vitimas direta e indiretamente ligados à tragédia, com vistas à realização do documentário intitulado Césio 137 O Brilho da Morte.

A sintaxe e a gramática audiovisual foram construídas como resultado da análise mais exaustiva do conteúdo dos episódios enunciados na linguagem dos atores sociais que sobreviveram a referida tragédia.

$\mathrm{O}$ estudo analítico das morfologias vigentes na vida social de grupos humanos ou comunitários em áreas e situações de conflitos e tragédias deveria ser, então, uma fase essencial do método de concepção e explicação da obra documental.

O realizador atento ao seu contexto histórico e social, vivendo no ambiente urbano e nos limites de sua cultura globalizada, deve dar-se tempo para analisar, conhecer e ordenar os elementos das representações vigentes ali, tendo em conta, assim, que a expressão audiovisual exige conjugar diversas linguagens expressivas: plásticavisual, poética, sonora.

O filme documental não deve ser realizado, como se observa habitualmente, somente mediante o "facilismo operacional" das técnicas de funcionamento das atuais tecnologias audiovisuais cheias de efeitos e novidades que encantam o mundo pela beleza das aparências e o consumo de imagens. De modo geral, não se tem interesse pelas questões concernentes a forma e não se considera como principal vetor da obra audiovisual o conhecimento sistemático da realidade social e suas relações dialógicas com elementos vivos da expressão imagética - visual e sonora - que dão sentido e profundidade ao exercício do trabalho composicional.

Penso, então, que é imprescindível atingir a essência da morfologia das expressões artísticas para compreender a especificidade da linguagem do cinema documental como forma de dar a conhecer a profundidade da representação dos temas que abordamos. 
Entretanto, penso também que se deve aplicar nesse processo de criação audiovisual a analise critica com a intenção de alcançar os segredos que estão por traz dos fenômenos sociais e culturais investigados.

A ressonância alcançada na associação da pesquisa social e os procedimentos de criação artística na produção do curta metragem “Césio 137-O Brilho da Morte", traduz, de certa maneira, nossas preocupações acerca da coesão e da especificidade do cinema documental.

Penso que uma obra documental realizada a partir de temática emergente como a do Césio 137, em que o documentarista está inserido no ambiente em que ele é também ator social da mesma história, inevitavelmente, como cineasta, deve procurar elaborar uma análise crítica e um discurso militante longe de uma concepção pessoal sujeita a juízos e inferências infundadas ou pré-estabelecidas.

Militante no sentido de realizar uma leitura crítica da obra audiovisual como objeto e peça de intervenção política em defesa do grupo social atingido, desprotegido em seus direitos e excluído dos benefícios do poder público.

Assim, a obra artística, como forma de disseminar idéias, pode ganhar espaço na sua difusão social na medida em que ela passa a fazer parte de um processo de reflexão de temas pontuais, no contexto cultural em que foi produzida.

O cinema nasceu social, motivado pela pesquisa cientifica sob o ponto de vista instrumental, para documentar o homem e sua especificidade, como forma de compreender a diversidade cultural, a riqueza material e imaterial e a produção do conhecimento laborado na passagem da natureza à cultura.

No decorrer de cem anos os vetores do olhar cinematográfico do ocidente, dirigiram-se para temas enunciados na América, Ásia e África por documentaristas de diversas nacionalidades que abordaram a representação social e cultural à luz de concepções muito diversas, não somente como registro da realidade, mas, sobretudo, como nova forma de articulação artística por meio da objetividade imagética de construção do "outro".

A variedade da produção documental inaugura este gênero cinematográfico a partir de obras como Nanook of the North (1922), Moana(1926) de Flaherty, Tabu (1928-31) co-realizado por Flaherty e Murnau; Berlin, Sinfonia de uma Cidade Grande (1927) de Ruttman, Drifters (1929) de John Grierson, O Homem da Câmera (1929) de Vertov, A Propos de Nice (1929) de Jean Vigo, O trem em marcha (1932) de Aleksandr Medvedkin, entre outros, conduzindo, assim, o campo do documental para a vida 
cotidiana e seus valores expressivos. Esta geração colocou em evidência a especificidade do gênero documental, colocando a ética como critério de contar a história a partir da representação documental

O cinema que nasceu documental, social e silencioso e deu voz ao mundo.

\section{Referências}

ALEXANDRE, Marcos. Representação Social: uma genelogia do conceito. In: COMUM. V. 10,N.23, PP. 122-138, jul/dez.Rio de Janeiro,2004.

ALVES, Gláucia Lelis. Abadia de Goiás e o Acidente com o Césio 137: um projeto hegemônico do Estado. Monografia, orientação $\operatorname{Prof}^{\mathrm{a}}$ Dr $^{\mathrm{a}}$ Walderez Loureiro Miguel, Dep. Serviço Social, Universidade Católica de Goiás, 2002.

CARRIÈRE, Jean-Calude. A linguagem secreta do cinema. Editora Nova Fronteira, Rio de Janeiro, 1995.

GUIDI, MARIO ARTURO ALBERTO. De Altamira a Palo Alto: a busca do movimento. Tese de Livre Docência, Escola de Comunicações e Artes-USP, 1991.

MITRY, Jean. Histoire du Cinema: Art et Industrie, I. 1895-1915. Éditinos Universitaires, Paris, 1967.

NEVES, Sueli Almeida. Memória e Cotidiano -quando os radioacidentados militares entram em cena. Monografia , orientação $\operatorname{Prof}^{a} \operatorname{Dr}^{a}$ Walderez Loureiro Miguel, Dep. Serviço Social, Universidade Católica de Goiás, 2002.

RENOIR, Jean. Ecrits (1926-1971). Ramsai Poche Cinema, Pierre Belfond, Paris, 1974. ROMAGUERA I THEVENET. Fuentes y Documentos del Cine, Imagem Filmica, Editorial Fontamara, Barcelona, 1985.

WIEDERHECKER, Cleyce Louise. Cidade, Promessa, Exclusão - O césio 137 em Goiânia. Tese de Doutorado em Geografia, Universidade de São Paulo, 1988. 